\title{
Brittleness Evaluation of Shale Based on the Brazilian Splitting Test
}

\author{
Bing Hou, ${ }^{1,2}$ Yijin Zeng $\left(\mathbb{D},{ }^{1,3}\right.$ Meng Fan, ${ }^{2}$ and Dandan $\mathrm{Li}^{1,3}$ \\ ${ }^{1}$ State Key Laboratory of Shale Oil and Gas Enrichment Mechanisms and Effective Development, Beijing 100101, China \\ ${ }^{2}$ State Key Laboratory of Petroleum Resources and Engineering, China University of Petroleum-Beijing, Beijing 102249, China \\ ${ }^{3}$ Sinopec Research Institute of Petroleum Engineering, Beijing 100101, China \\ Correspondence should be addressed to Yijin Zeng; yijinzeng@163.com
}

Received 15 December 2017; Accepted 28 February 2018; Published 16 April 2018

Academic Editor: Xiangzhao Kong

Copyright (C) 2018 Bing Hou et al. This is an open access article distributed under the Creative Commons Attribution License, which permits unrestricted use, distribution, and reproduction in any medium, provided the original work is properly cited.

\begin{abstract}
Brittleness is an important mechanical parameter of shale reservoirs and has a significant effect on hydraulic fracturing. Traditional evaluation methods of shale brittleness are mainly based on complete stress-strain curves under compressive loading, which can barely describe the fracture characteristics of shale during hydraulic fracturing. This paper proposes to define the brittleness index based on the Brazilian splitting test and establishes a corresponding evaluation method, forming a tensile brittleness evaluation system for noncontinuous shale. The Brazilian splitting test and discrete element numerical simulation are carried out to study the crack distribution characteristics after tensile failure as well as the influence of anisotropy and scale effect on the brittleness of shale. The results show that the tensile brittleness index is more accurate and sensitive to condition changes than the compressive brittleness index. The experimental shale cores are from the Longmaxi formation, Silurian system, Sichuan basin.
\end{abstract}

\section{Introduction}

Rock brittleness is the key index for evaluating reservoir geomechanical properties. It has a significant impact on hydraulic fracturing results. Scholars have different opinions on the definition of rock brittleness. Ramsay [1] defined brittleness as the ability to overcome intrinsic cohesion forces when brittle failure occurs in a material. Morley and Heteny $[2,3]$ proposed that brittleness is a deficiency of plasticity during material failure. Obert and Duvall [4] conducted experiments using rocks and suggested that the material slightly reaches or exceeds its yield strength during loading. The industry also put forward specific evaluation methods for calculating the brittleness index [5]. Rickman et al. [6] showed that rock brittleness is mainly influenced by the elastic modulus and Poisson ratio. They summarized their results from Barnett shale and proposed that the lower the Poisson ratio and the higher the elastic modulus are, the more brittle the rocks would be. Li et al. [7] considered the entire rock failure process based on the complete stress-strain curve, evaluated brittleness using mechanical properties before and after the curve peak, and calculated the comprehensive brittleness index by combining the empirical formulas. Jarvie et al. [8] proposed a method to calculate brittleness index based on the brittle mineral content. In 2009, Wang and Gale [9] improved Jarvie et al.s definition of brittleness by classifying dolomite as brittle mineral and organic matter as ductile mineral. In 2010, Chong et al. [10] used the brittle mineral content in shale combined with geomechanical parameters to represent the shale brittleness, which provides a quantitative basis for evaluating shale brittleness.

Jin et al. [11] defined the brittleness from the energy point of view. They suggested that rock is ductile if it absorbs a great deal of energy before failure; otherwise, the rock is brittle. The energy method in fracture mechanics can be used to reliably and quantitatively evaluate rock brittleness. The increase of rock ductileness can be viewed as an increase of energy dissipation [12]. Chen et al. [13] put forward a brittleness evaluation method based on energy dissipation mechanism. They indicated that the larger the energy 


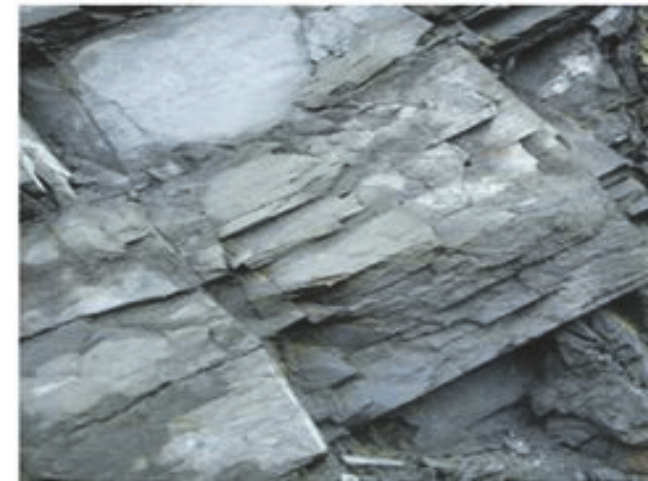

FIGURE 1: Shale outcrops in Longmaxi formation.

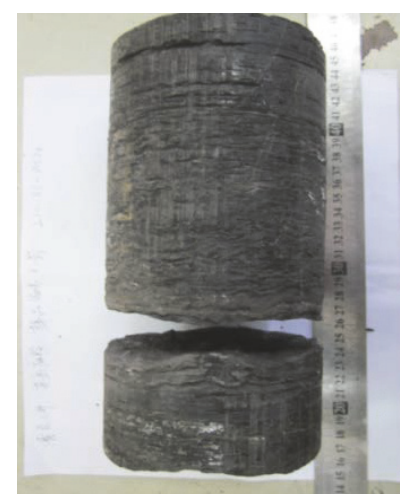

FIgURE 2: Cores from the Longmaxi shale gas reservoir. dissipation, the lower the brittleness index. Cai et al. [14] conducted tensile experiments to study fracture initiation and propagation behavior in brittle rocks. They believed that there is a correlation between the brittleness index and fracture initiation stress. During the process of tensile failure in rocks, microfractures initiate and extend until the sample is broken. The corresponding strength is almost equal to the rock tensile strength [15]. Once a microcrack occurs in tensile experiments in brittle rocks, the crack will propagate unstably [16], which shows that the rock tensile testing results agree with the fracture characteristics in shale hydraulic fracturing. Therefore, this paper overcomes the limitation of using the prepeak mechanical parameters and postpeak stress attenuation degree to represent rock brittleness, proposes the definition of the brittleness index based on tensile failure, presents a comprehensive evaluation method and prediction model, and forms a theoretical system for evaluating shale brittleness under tensile conditions.

\section{Experimental Study of Shale Brittleness under Brazilian Splitting Testing}

2.1. Shale Sampling and Processing. Shale cores are drilled from the $2400 \mathrm{~m}$ deep shale reservoir in the Longmaxi formation, Silurian system, Sichuan Basin. The shale outcrops of the Longmaxi formation have well-developed beddings and cracks, and most joints are beddings or cracks perpendicular to the bedding planes (Figure 1). By contrast, the downhole cores from the Longmaxi formation have high-density thin bedding lines on the sample surface (Figure 2).

Brazilian splitting tests are conducted on outcrops and downhole cores from the Longmaxi formation to evaluate the brittleness characteristics of shale.

Cylinder samples with a diameter of $25 \mathrm{~mm}$ and a height of $50 \mathrm{~mm}$ are drilled parallel to the bedding planes. Then, they are cut into disk samples with a diameter of $25 \mathrm{~mm}$ and thickness of $5 \mathrm{~mm}$ (Figure 3). The test angle is defined as the angle between the loading direction and the normal direction of the bedding planes. To study the brittle characteristics of shale under different test angles, a loading line parallel to the loading direction is drawn on each sample before the test.
2.2. Brazilian Splitting Test. The apparatus used to conduct the Brazilian splitting test is the RTR-1500 HTHP triaxial rock testing system produced by GCTS located in Tempe, Arizona, USA, as shown in Figure 4. The system is capable of testing and analyzing the acoustic velocity, permeability, in situ stress, and mechanical strength of cores in a hightemperature and high-pressure environment.

At the beginning of the test, samples are placed into an arc-shaped fixture, ensuring that the loading line is aligned with the loading direction (Figure 5). The test rack is then placed on the compression machine, which exerts small radial loading on samples through a pressure servo. During the tests, the loading stress increases slowly and steadily and the pressure head goes down constantly at a predefined speed until the sample fails.

2.3. Experimental Scheme and Results. Factors such as the buried depth, mineral content, coring angle, and test condition have a large impact on the mechanical characteristics of shale [17]. Therefore, core samples are divided into 4 groups according to their buried depth. In the second group, the test angles are set at $0^{\circ}, 45^{\circ}$, and $90^{\circ}$. Since the loading rate has an impact on the mechanical behavior of rocks [18], different loading rates are used to analyze the sensitivity of shale brittleness to the loading rate. The experimental scheme is shown in Table 1.

Strain-stress curves are recorded during the experiments. By comparing the results under different test conditions (Figure 6), it can be found that shale outcrops have the lowest tensile strength. As the buried depth increases, the tensile strength of cores increases gradually. The mechanical parameters of shale are highly sensitive to the loading rate. The tensile strength of shale outcrops decreases gradually as the loading rate increases. The loading rate has an even larger impact on downhole cores, and the effect is also highly related to the bedding plane direction. Specifically, when the test angle is $45^{\circ}$, the tensile strength of downhole shale samples increases as the loading rate increases. Under high loading rates, shale tends to fail and forms multiple splitting planes; however, under low loading rates, tensile cracks are difficult to develop. Hence, the loading rate is set between 0.01 and $0.02 \mathrm{~mm} / \mathrm{min}$ to guarantee the accuracy of the test results. 


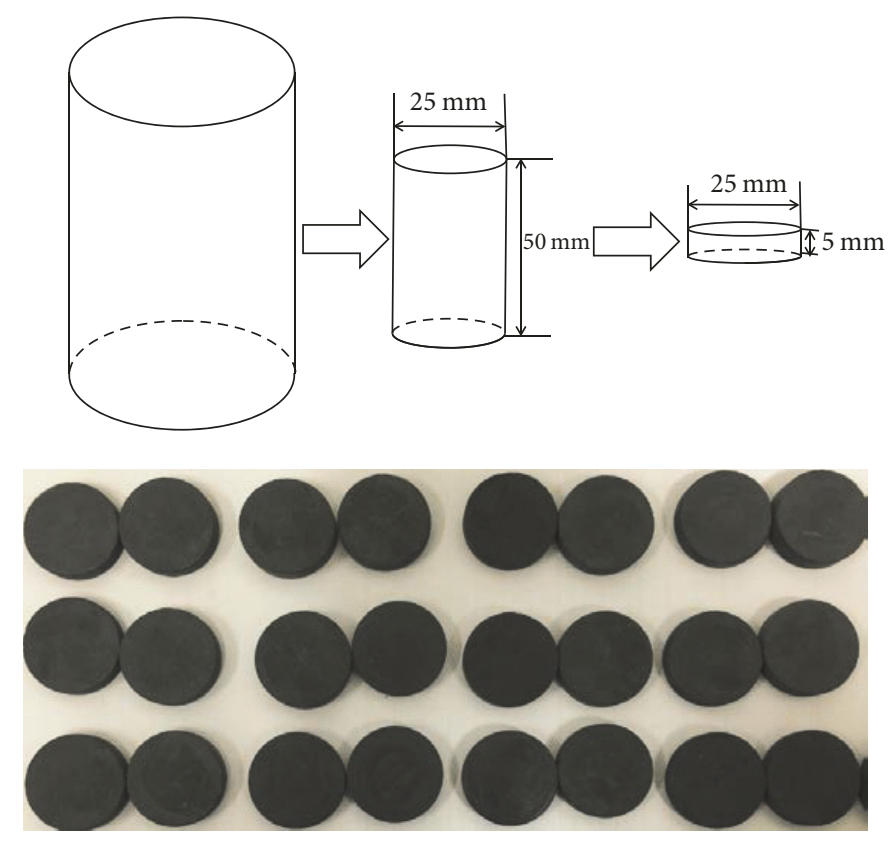

FIGURE 3: Schematic diagram of cores and disks used for Brazilian splitting testing.

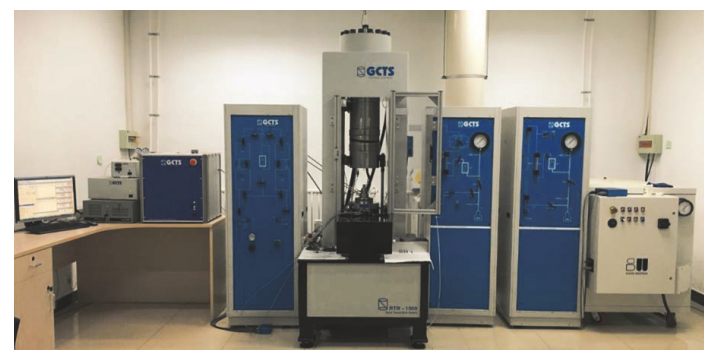

FIGURE 4: RTR-1500 HTHP triaxial rock testing system.

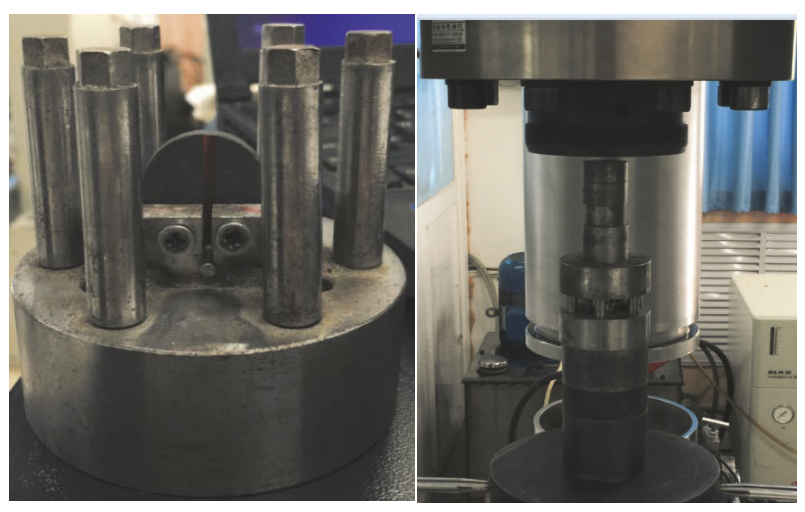

FIGURE 5: Brazilian splitting test rack.

\section{Tensile Brittleness Evaluation Model Based on the Brazilian Splitting Test}

3.1. Mechanism of Shale Brittleness Evaluation under Tensile Loading. Shale with developed cracks has high brittleness
[19]. However, when a triaxial compression test is conducted to evaluate brittleness, the fracture closure behavior strongly affects the experiment results (as shown in Figure 7(a)). On the contrary, when shale is under tensile loading, the bonding strength of the bedding planes decreases, forming a large number of microcracks, which then propagate and intersect each other. Hence, the prepeak part of the stress-strain curve of shale under tensile loading exhibits an obvious fluctuation behavior, reflecting the brittle characteristics of shale (as shown in Figure 7(b)).

SEM is utilized to scan the failed shale samples (as shown in Figure 8). At the initial phase of brittle failure, the cohesion and bonding forces between mineral grains decrease as the loading stress increases, causing the initiation of cracks in samples. As loading stress continues to increase, microcracks start to propagate and intersect with each other, forming macroscale cracks. When the brittle failure enters the stable phase, the friction force between fracture surfaces increases as the loading stress increases. During the stable phase, macroscale cracks bear most of the loading. The friction force vanishes the instant it reaches the maximum bearing capacity of the fracture surfaces, causing brittle failure of the rocks.

Three types of failure characteristics can be observed after Brazilian splitting testing (Figure 9).

(1) Tensile Splitting. The fracture plane has a linear shape, and its direction is parallel to the loading direction and perpendicular to the tensile stress direction. Under this circumstance, the surface profile is rough and the sample has the highest brittleness.

(2) Tensile-Shear Failure. The fracture plane has a half-moon shape. Due to the increase of the bonding strength between bedding surfaces, rock failure is suppressed and fractures 

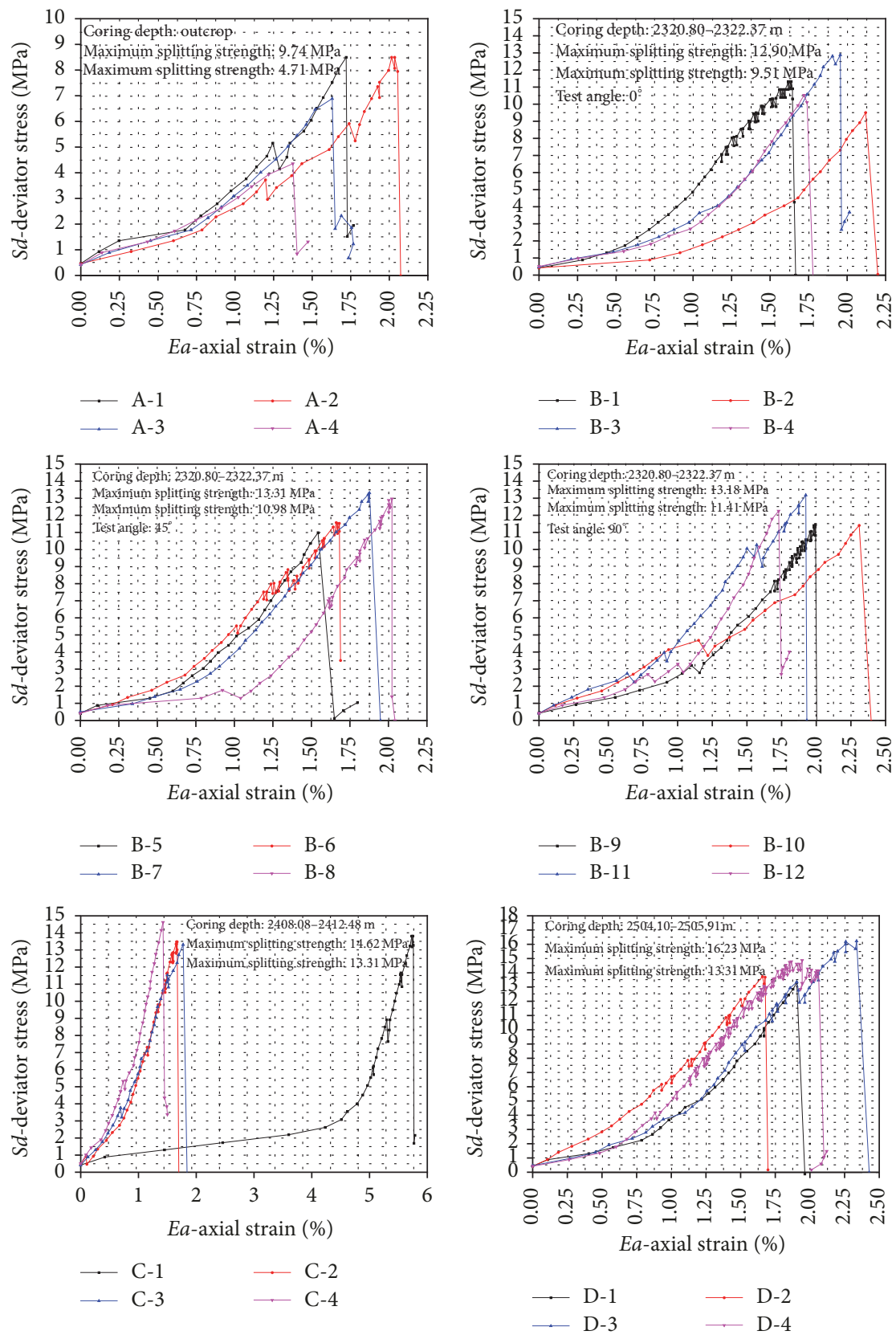

Figure 6: Stress-strain curves of the Brazilian splitting test.

propagate along the bedding planes and surrounding microcracks, causing tensile-shear failure. The shale brittleness under this condition is lower than the brittleness of shale which exhibits tensile splitting characteristics.

(3) Shear Failure. The fracture plane has a short curve shape. The fracture surfaces slip along the bedding planes, during which the shear force plays a leading role in rock failure. The shale brittleness is the lowest under this circumstance.

In the field fracturing operation process, when the wellbore internal pressure increases instantly, many microcracks form around natural weak planes under tensile loading before formation fracture. Hence, the results are more consistent with the field condition when the brittle rock characteristics are evaluated under tensile loading.

\subsection{Evaluation Model of Shale Brittleness under Tensile Loading}

3.2.1. Brittleness Index $\mathrm{BI}_{E}$ Based on Elastic Parameters. Referring to the model proposed by Rickman et al. [6] that evaluates rock brittleness under compressive loading based on Young's modulus and Poisson's ratio, the elastic parameters of rock under tensile loading are used to evaluate shale 


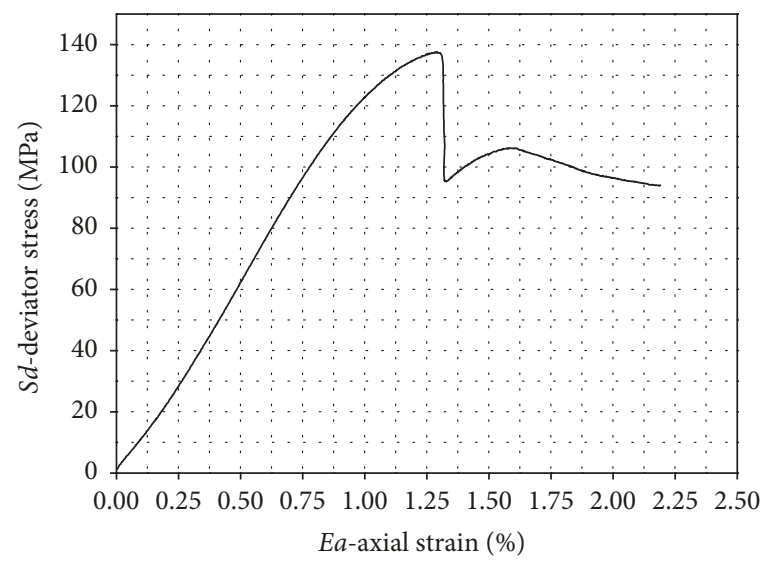

(a)

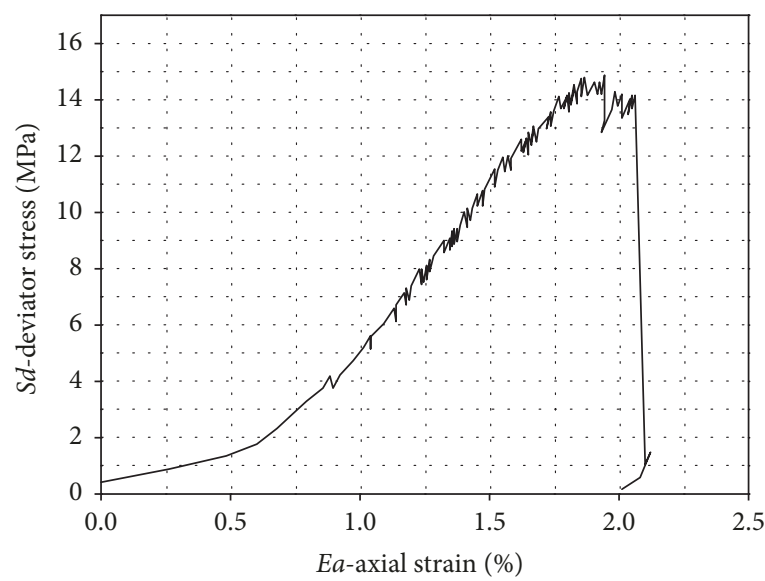

(b)

FIGURE 7: Stress-strain curves of shale under compressive and tensile loading.

TABle 1: Experimental scheme.

\begin{tabular}{|c|c|c|c|c|}
\hline Coring depth & Group & Sample number & Test angle $\left({ }^{\circ}\right)$ & Loading rate $(\mathrm{mm} / \mathrm{min})$ \\
\hline \multirow{4}{*}{ Outcrop } & \multirow{4}{*}{1} & A-1 & \multirow{4}{*}{ l } & 0.01 \\
\hline & & A-2 & & 0.02 \\
\hline & & A-3 & & 0.04 \\
\hline & & A- 4 & & 0.05 \\
\hline \multirow{4}{*}{$2320.80 \mathrm{~m}-2322.37 \mathrm{~m}$} & \multirow{4}{*}{$2(1)$} & B-1 & \multirow{4}{*}{$0^{\circ}$} & 0.01 \\
\hline & & B-2 & & 0.02 \\
\hline & & B-3 & & 0.04 \\
\hline & & B-4 & & 0.05 \\
\hline \multirow{4}{*}{$2320.80 \mathrm{~m}-2322.37 \mathrm{~m}$} & \multirow{4}{*}{$2(2)$} & B-5 & \multirow{4}{*}{$45^{\circ}$} & 0.01 \\
\hline & & B-6 & & 0.02 \\
\hline & & B-7 & & 0.04 \\
\hline & & B-8 & & 0.05 \\
\hline \multirow{4}{*}{$2320.80 \mathrm{~m}-2322.37 \mathrm{~m}$} & \multirow{4}{*}{$2(3)$} & B-9 & \multirow{4}{*}{$90^{\circ}$} & 0.01 \\
\hline & & B-10 & & 0.02 \\
\hline & & B-11 & & 0.04 \\
\hline & & B-12 & & 0.05 \\
\hline \multirow{4}{*}{$2408.08 \mathrm{~m}-2412.48 \mathrm{~m}$} & \multirow{4}{*}{3} & $\mathrm{C}-1$ & \multirow{4}{*}{ l } & 0.01 \\
\hline & & $\mathrm{C}-2$ & & 0.02 \\
\hline & & $\mathrm{C}-3$ & & 0.04 \\
\hline & & $\mathrm{C}-4$ & & 0.05 \\
\hline \multirow{4}{*}{$2504.10 \mathrm{~m}-2505.91 \mathrm{~m}$} & \multirow{4}{*}{4} & D-1 & \multirow{4}{*}{ l } & 0.01 \\
\hline & & D-2 & & 0.02 \\
\hline & & D-3 & & 0.04 \\
\hline & & D-4 & & 0.05 \\
\hline
\end{tabular}

brittleness. Brazilian splitting tests are conducted to obtain Young's modulus and Poisson's ratio of shale under tensile loading. The elastic parameters are normalized to calculate the shale brittleness index $\mathrm{BI}_{E}$ under tensile loading:

$$
\mathrm{BI}_{E}=\alpha \bar{E}+\beta \bar{v}
$$

where $\bar{E}$ is the normalized Young's modulus (GPa), $\bar{\nu}$ is the normalized Poisson's ratio, and $\alpha$ and $\beta$ are correction factors. The value range of $\mathrm{BI}_{E}$ is $0 \sim 1$. The more brittle the rock is, the closer $\mathrm{BI}_{E}$ is to 1 .

3.2.2. Brittleness Index $\mathrm{BI}_{P t}$ Based on the Curve Peak Characteristics. Smaller rock deformation before reaching peak 


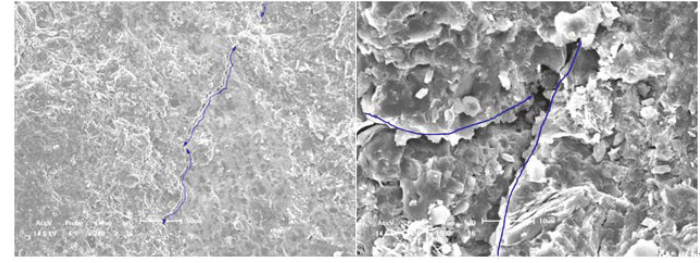

FIGURE 8: Intersection mode of microcracks of shale under tensile failure.

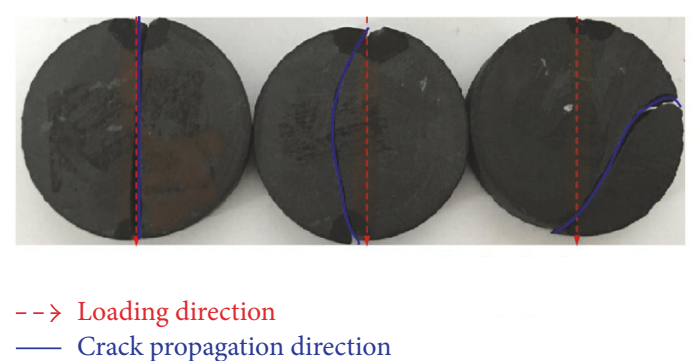

FIgURE 9: Three failure modes of shale in the Brazilian splitting test.

strength indicates a lower ductile deformation degree and higher brittleness [7]. The peak point in the stress-strain curve of rocks under tensile loading is chosen as the feature point of rock failure. Tensile strength characterizes the ability of rocks to resist damage, and the deformation at the peak point characterizes the deformation degree of rocks when they fail. Hence, the brittleness index $\mathrm{BI}_{P t}$ based on the peak characteristics of the stress-strain curve can be calculated as follows:

$$
\mathrm{BI}_{P t}=\overline{\left(\frac{P_{t}}{\varepsilon_{t}}\right)}
$$

in which $P_{t}$ is the tensile strength $(\mathrm{MPa})$ and $\varepsilon_{t}$ is the deformation at peak point (\%).

\subsubsection{Brittleness Index $\mathrm{BI}_{R}$ Based on Energy Dissipation.} From the perspective of energy dissipation, rock brittleness can be evaluated by the magnitude of the rock intrinsic cohesion and crack propagation resistance, and the latter reflects the unrecoverable nature of rock ductile failure [13]. The ratio of the rock intrinsic cohesion to the crack propagation resistance under tensile loading can be used to quantify the brittleness of rocks; thus, the brittleness index $\mathrm{BI}_{R}$ under tensile loading can be calculated as follows:

$$
\mathrm{BI}_{R}=\overline{\left(\frac{R_{0}}{R_{\mu}{ }^{\infty}}\right)}
$$

where $R_{0}$ is the intrinsic cohesion of rocks and $R_{\mu}{ }^{\infty}$ is the total fracture propagation resistance exerted by the frontal zone when stress reaches the peak value.

Three types of brittleness are obtained via the above three methods. Cores with brittleness indexes of a higher
TABLE 2: Brittleness indexes with large dispersion degree.

\begin{tabular}{lcccc}
\hline Sample number & $\mathrm{BI}_{E}$ & $\mathrm{BI}_{P t}$ & $\mathrm{BI}_{R}$ & Standard deviation \\
\hline B-1 & 0.62 & 0.80 & 0.11 & 0.3579 \\
B-6 & 0.51 & 0.76 & 0.15 & 0.3066 \\
B-10 & 0.67 & 0.27 & 0.18 & 0.2608 \\
B-12 & 0.19 & 0.70 & 0.88 & 0.3579 \\
C-1 & 0.16 & 0.02 & 0.74 & 0.3817 \\
C-2 & 0.54 & 0.96 & 0.10 & 0.4300 \\
D-2 & 0.50 & 1.00 & 0.17 & 0.4178 \\
D-3 & 0.35 & 0.70 & 0.08 & 0.3108 \\
\hline
\end{tabular}

dispersion degree are chosen as objects to compare the brittleness indexes obtained by different methods, as shown in Table 2.

It can be seen from the results that the three types of brittleness indexes are inconsistent with each other when they are used to evaluate rock brittleness. If only one of the three methods is used for evaluation, other factors affecting rock brittleness will be neglected, leading to uncertainties in the brittleness evaluation. Hence, a multiple regression method is utilized to calculate the comprehensive brittleness index of rock under tensile loading:

$$
I_{\mathrm{BT}}=m_{1} \mathrm{BI}_{E}+m_{2} \mathrm{BI}_{P t}+m_{3} \mathrm{BI}_{R}+C,
$$

where $m_{1}, m_{2}$, and $m_{3}$ are weight coefficients and $C$ is the regression correction coefficient.

Calculation results with errors less than 0.1 are chosen to obtain the unknown coefficients in (4). The resulting equation is as follows:

$$
I_{\mathrm{BT}}=0.3825 \mathrm{BI}_{E}+0.6218 \mathrm{BI}_{P t}+0.1591 \mathrm{BI}_{R}-0.0376
$$

where the regression coefficients for $\mathrm{BI}_{E}, \mathrm{BI}_{P t}$, and $\mathrm{BI}_{R}$ are $0.8075,0.4271$, and 0.6615 , respectively.

The comprehensive brittleness index is used to evaluate the shale core brittleness, the results of which are shown in Table 3.

Compared with the brittleness index calculated under compressive loading, the brittleness index calculated under tensile loading is more sensitive and accurate.

\section{Tensile Brittleness Evaluation Model Based on the Discrete Element Method}

To simulate the failure and crack propagation process of shale during Brazilian splitting testing and verify the accuracy of the established brittleness evaluation model, the discrete element method is utilized to establish the Brazilian splitting test model for layered shale and conduct a numerical simulation on the tensile brittle failure of shale. The influence of factors such as the bedding plane angle and core scale effect on the tensile brittleness is analyzed based on the simulation results.

4.1. Discrete Element Model for the Tensile Brittleness Evaluation. A uniaxial compression simulation model is first 
TABLE 3: Comprehensive brittleness index of shale.

\begin{tabular}{lcc}
\hline Coring depth & Sample number & $\begin{array}{c}\text { Comprehensive } \\
\text { brittleness index } \\
\text { BT }\end{array}$ \\
\hline \multirow{2}{*}{ Outcrop } & A-1 & 0.32 \\
& A-2 & 0.5 \\
\hline \multirow{2}{*}{$2320.80 \mathrm{~m}-2322.37 \mathrm{~m}$} & B-1 & 0.71 \\
& B-3 & 0.59 \\
& B-4 & 0.43 \\
& B-7 & 0.68 \\
$2320.80 \mathrm{~m}-2322.37 \mathrm{~m}$ & B-8 & 0.62 \\
& B-9 & 0.58 \\
\hline \multirow{2}{*}{$2408.08 \mathrm{~m}-2412.48 \mathrm{~m}$} & B-10 & 0.42 \\
& B-12 & 0.61 \\
\hline \multirow{2}{*}{$2504.10 \mathrm{~m}-2505.91 \mathrm{~m}$} & C-2 & 0.75 \\
& C-4 & 0.87 \\
\hline & D-1 & 0.56 \\
& D-2 & 0.80 \\
& D-3 & 0.54 \\
& D-4 & 0.63 \\
\hline
\end{tabular}

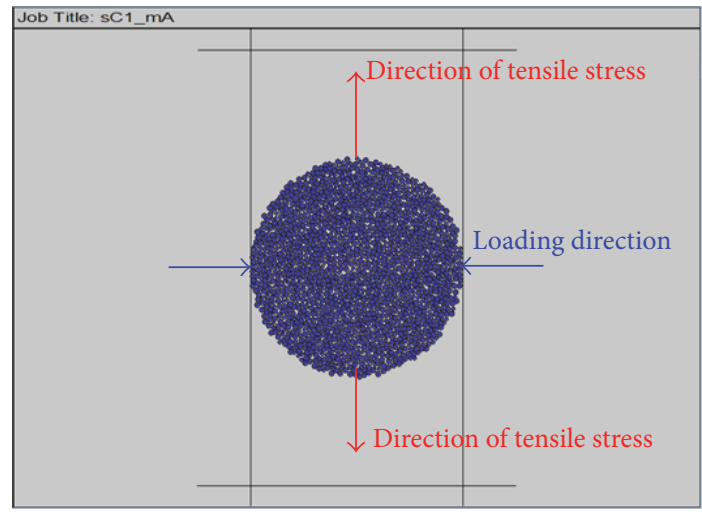

FIGURE 10: Schematic diagram of the loading direction.

established by PFC to help adjust the microscopic physical parameters by making the macroscopic physical parameters of the simulation model identical to those of the core samples used for laboratory uniaxial compression test. The detailed parameters of PFC model and the comparison between simulation model and rock sample are listed separately in Tables 4 and 5. The loading direction in the simulation is shown in Figure 10.

Cracks initiate from the center of the disk. As loading increases, cracks propagate along the diameter whose direction is perpendicular to the tensile stress. The propagation rate continues to increase until the loading stress reaches the failure strength and the crack penetrates through the entire disk (Figure 11). The number of cracks is related to the mechanical parameters of the samples. The more brittle

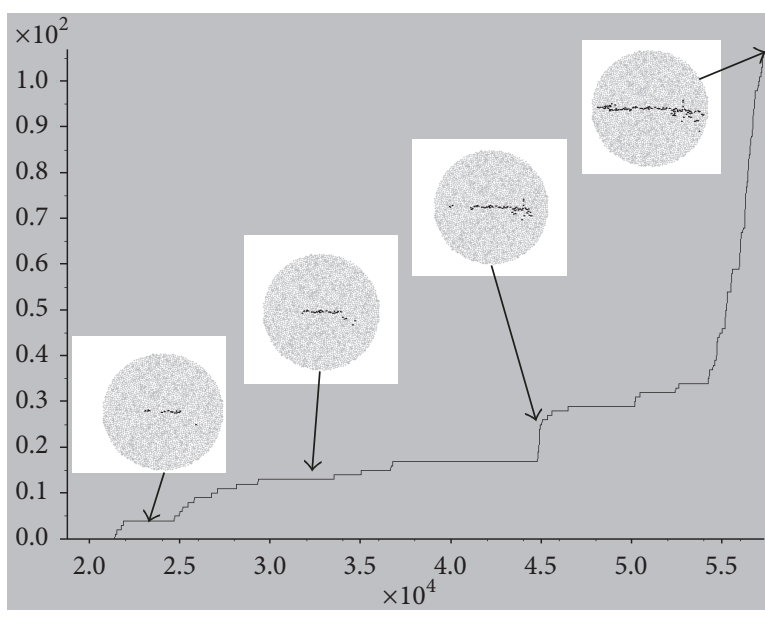

FIGURE 11: Crack propagation process.

the rock is, the more cracks would form. By recording the crack number of each simulation, a relationship between the tensile brittleness index and the crack number is established to evaluate the reliability of the proposed method.

Numerical simulations of shale tensile testing under different conditions are conducted to obtain the crack distribution characteristics of samples with different tensile brittleness indexes. The simulation results show that the higher the brittleness index is, the more cracks would form and the more complex the failure mode is (Table 6). Hence, the accuracy of the tensile brittleness index evaluation method is verified by the crack propagation behavior in numerical simulations.

\subsection{Factors Affecting the Evaluation of Tensile Brittleness}

4.2.1. Influence of Anisotropy on Shale Brittleness. By changing the tensile strength and shear strength between different particles layers (i.e., adding weak bedding planes to the model), 5 different models with different angles between the tensile stress and bedding planes, namely, $0^{\circ}, 30^{\circ}, 45^{\circ}$, $60^{\circ}$, and $90^{\circ}$, are established to simulate the different brittle characteristics of shale with different bedding plane angles (Figure 12).

Changing the bedding plane angles has a large impact on crack initiation and propagation. Many microcracks develop around weak bedding planes, but a large difference exists in the number of cracks when the angles between the tensile stress and bedding planes are different. Cracks may also reorient themselves when the direction of the bedding planes is not consistent with that of the tensile stress. By combining the results of the numerical simulation and laboratory Brazilian splitting tests, it can be seen that as the angle between the bedding planes and tensile stress increases, the brittle characteristics of shale first increase and then decrease. When the angle is between 30 and $60^{\circ}$, shale with weak bedding planes has the highest brittleness index under tensile stress (Figure 13).

In the numerical simulation, the number of microcracks is the highest when the bedding plane angle is at 45 degrees 


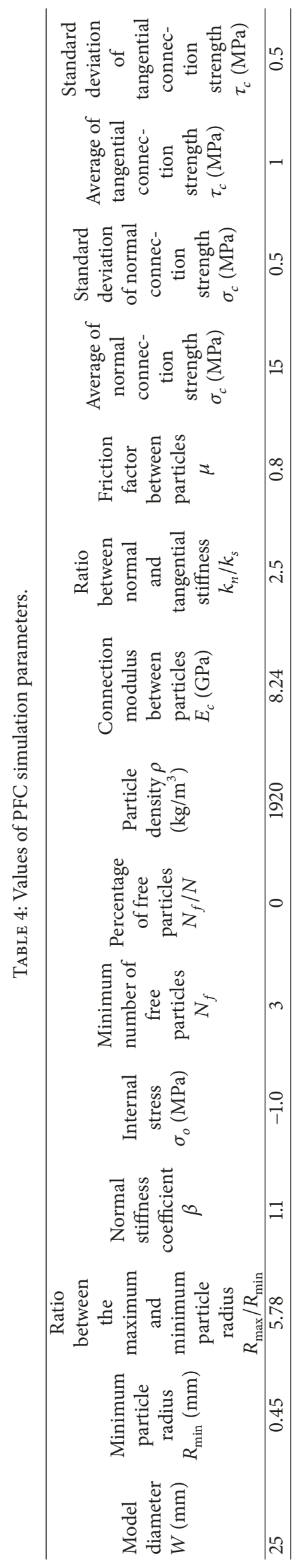



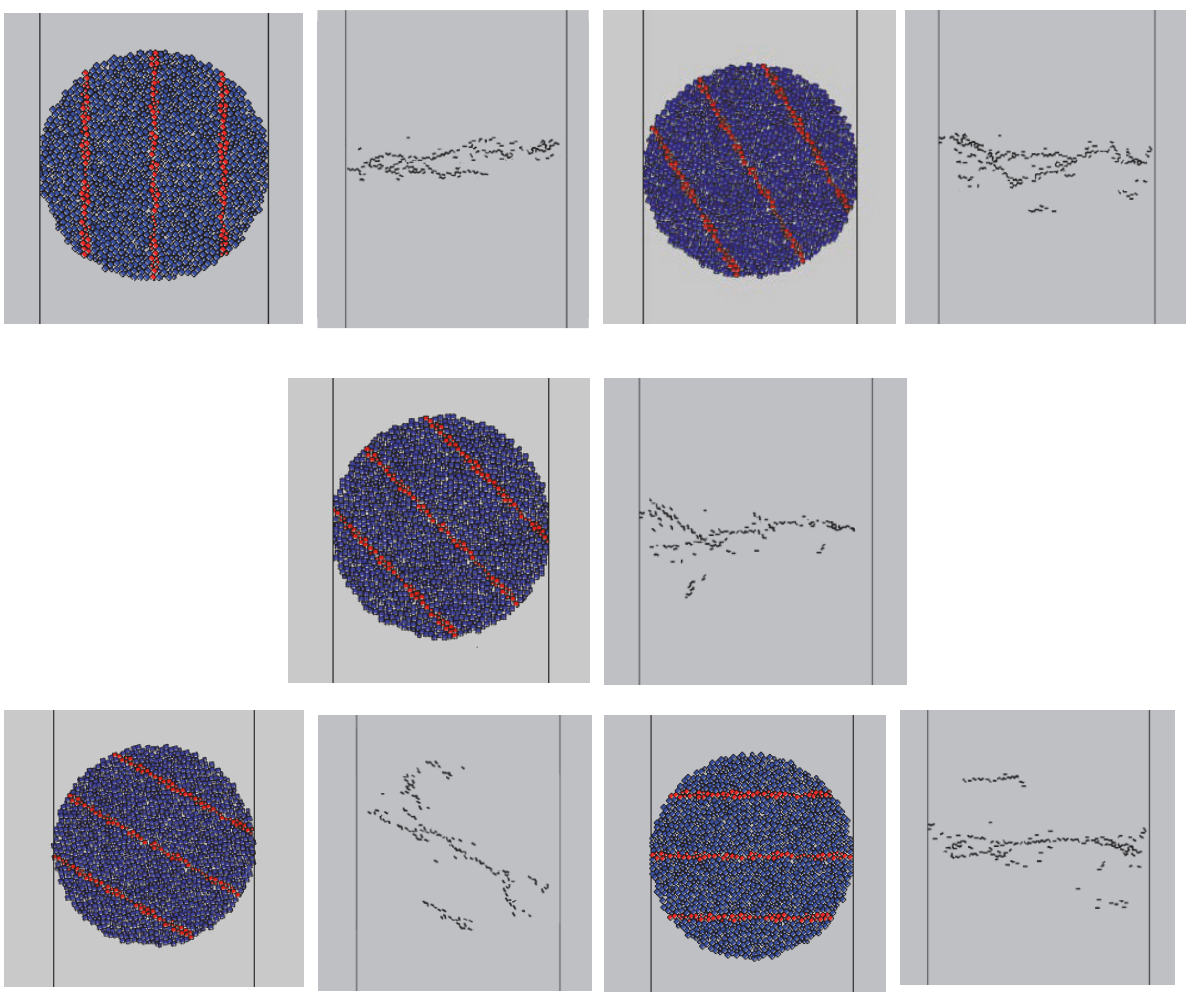

FIGURE 12: Different crack propagation characteristics of shale with different bedding plane angles (the loading direction is vertical).

TABLE 5: Comparison between the mechanical parameters of indoor experiment and PFC model.

\begin{tabular}{lccccc}
\hline & $\begin{array}{c}\text { Poisson's } \\
\text { ratio }\end{array}$ & $\begin{array}{c}\text { Elastic } \\
\text { modulus } \\
(\mathrm{GPa})\end{array}$ & $\begin{array}{c}\text { Failure } \\
\text { load } \\
(\mathrm{kN})\end{array}$ & $\begin{array}{c}\text { Peak } \\
\text { strain } \\
(\%)\end{array}$ & $\begin{array}{c}\text { Tensile } \\
\text { strength } \\
(\mathrm{MPa})\end{array}$ \\
\hline $\begin{array}{l}\text { Indoor } \\
\text { experiment }\end{array}$ & 0.1 & 11.14 & 3.2 & 1.728 & 13.48 \\
$\begin{array}{l}\text { PFC model } \\
\begin{array}{l}\text { Numerical } \\
\text { simulation error }\end{array}\end{array}$ & 0.103 & 11.251 & 3.225 & 1.780 & 13.785 \\
\hline
\end{tabular}

due to the setting cohesive force between particle balls and the friction factor between bedding plane surfaces.

4.2.2. Influence of the Scale Effect on the Brittleness of Shale. By simulating Brazilian splitting tests with different disk sizes, the scale effect influence on shale brittleness is studied by combining the comprehensive brittleness index model with the simulation results (Table 7).

The relationship between the comprehensive tensile brittleness index and disk diameter is drawn based on the simulation results, as shown in Figure 14.

There is a linear relationship between the number of microcracks and the diameter of the disk, but the variation is small. Similarly, the change in disk diameter has little influence on the comprehensive tensile brittleness index.

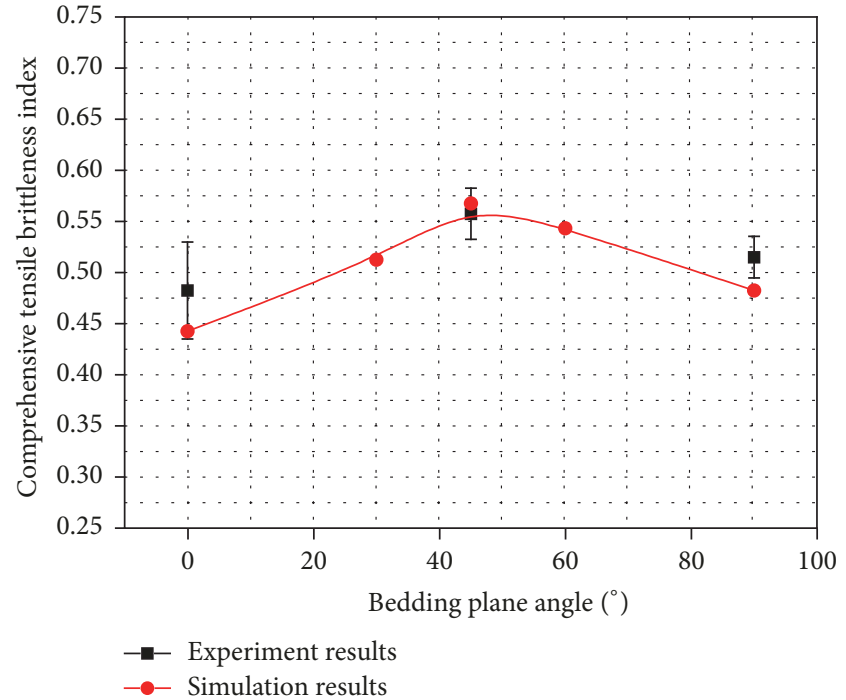

FIGURE 13: Influence of anisotropy on shale brittleness.

Hence, the scale effect of the core has very little influence on shale brittleness in laboratory experiments.

\section{Conclusions}

(1) Microcracks around shale bedding planes easily intersect with each other under tensile loading, causing cracks to 
TABLE 6: Crack distribution characteristics of samples in numerical Brazilian splitting tests.

\begin{tabular}{|c|c|c|}
\hline Sample number & Brittleness index & Number of cracks \\
\hline A-1 & 0.32 & 102 \\
\hline B-1 & 0.71 & 163 \\
\hline B-7 & 0.68 & 161 \\
\hline B-8 & 0.62 & 142 \\
\hline B-10 & 0.43 & 114 \\
\hline B-12 & 0.58 & 137 \\
\hline $\mathrm{C}-2$ & 0.75 & 175 \\
\hline $\mathrm{C}-4$ & 0.87 & 206 \\
\hline D-1 & 0.56 & 126 \\
\hline
\end{tabular}

propagate rapidly, leading to the brittle fracture of shale. Based on Brazilian splitting tests, a brittleness evaluation method of shale under tensile loading is proposed. Compared with compressive brittleness index which has a large
TABLE 7: Crack propagation characteristics of disk samples with different sizes.

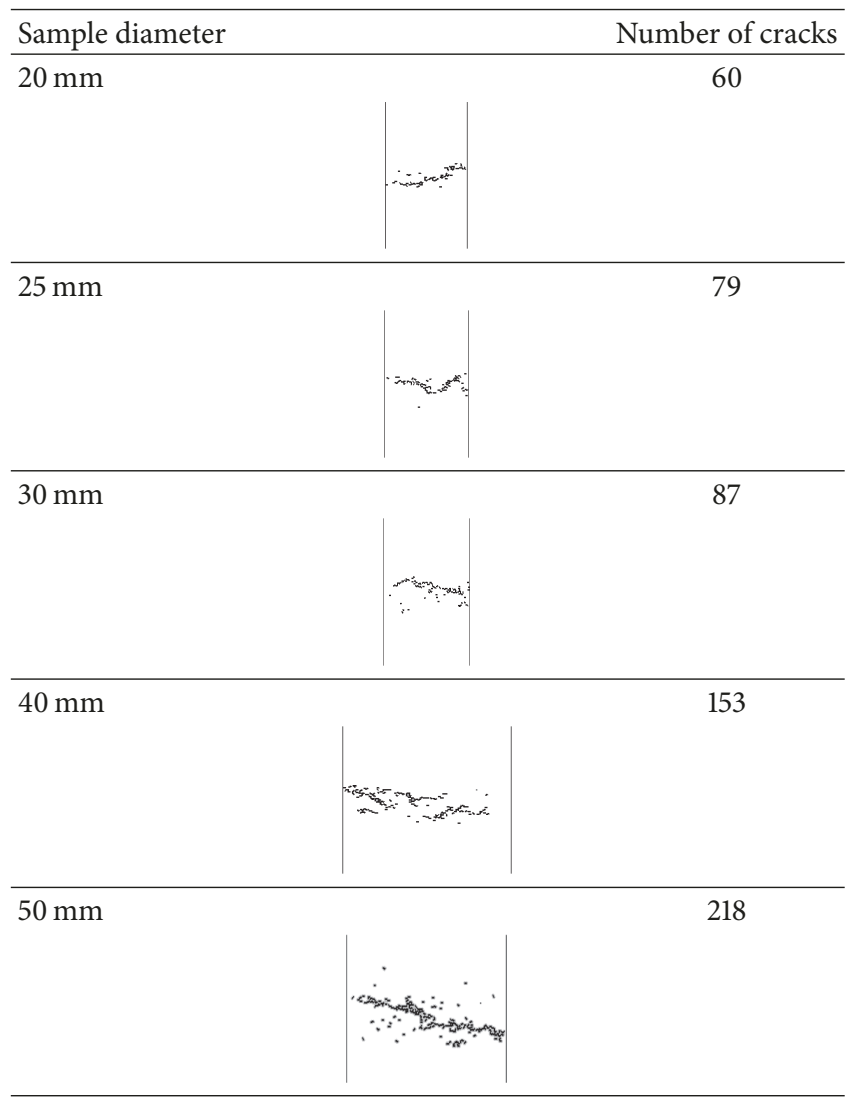

discreteness, the brittleness index calculated by the proposed method has a stronger sensitivity to environment change, thus giving a more accurate evaluation of shale brittleness during hydraulic fracturing.

(2) The results of the numerical Brazilian splitting tests show that samples with larger calculated tensile brittleness index have more microcracks after failure, verifying the reliability of the brittleness evaluation method based on Brazilian splitting tests.

(3) When the angle between the tensile stress and bedding planes is between 30 and $60^{\circ}$, shale has the highest tensile brittleness index. As the loading rate increases, the brittle characteristics of shale become more obvious, but the sample sizes used for the Brazilian splitting tests have little effect on the brittle characteristics of shale.

\section{Conflicts of Interest}

The authors declare that there are no conflicts of interest regarding the publication of this paper.

\section{Acknowledgments}

The authors are grateful for the support of NSFC (no. 51574260, no. 51490651, and no. 51521063) and Foundation of State Key Laboratory of Shale Oil and Gas Enrichment 


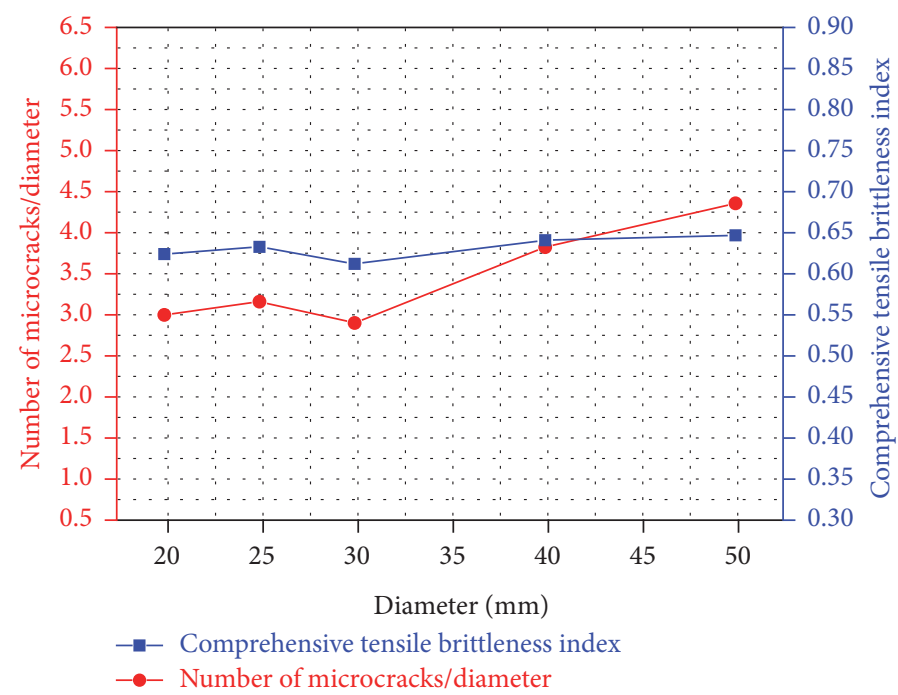

FIGURE 14: Influence of scale effect on shale brittleness.

Mechanisms and Effective Development (no. 10010099-16ZC0607-0019).

\section{References}

[1] J. G. Ramsay, Folding and Fracturing of Rocks, McGraw-Hill, London, UK, 1967.

[2] A. Morley, Strength of Materials, Longman Green, London, UK, 1944.

[3] M. Heteny, Handbook of Experimental Stress Analysis, John Wiley, New York, NY, USA, 1966.

[4] L. Obert and W. I. Duvall, Rock Mechanics and the Design of Structures in Rock, John Wiley, New York, NY, USA, 1967.

[5] V. Hucka and B. Das, "Brittleness determination of rocks by different methods," International Journal of Rock Mechanics and Mining Sciences \& Geomechanics Abstracts, vol. 11, no. 10, pp. 389-392, 1974.

[6] R. Rickman, M. Mullen, E. Petre, B. Grieser, and D. Kundert, "A practical use of shale petrophysics for stimulation design optimization: All shale plays are not clones of the Barnett Shale," in Proceedings of the SPE Annual Technical Conference and Exhibition, ATCE 2008, pp. 840-850, usa, September 2008.

[7] Q. Li, M. Chen, Y. Jin, F. P. Wang, B. Hou, and B. Zhang, "Indoor evaluation method for shale brittleness and improvement," Chinese Journal of Rock Mechanics and Engineering, vol. 31, no. 8, pp. 1680-1685, 2012.

[8] D. M. Jarvie, R. J. Hill, T. E. Ruble, and R. M. Pollastro, "Unconventional shale-gas systems: the Mississippian Barnett Shale of north-central Texas as one model for thermogenic shale-gas assessment," AAPG Bulletin, vol. 91, no. 4, pp. 475499, 2007.

[9] F. P. Wang and J. W. Gale, "Screening criteria for shalegas systems. Gulf Coast Association of Geological Societies Transactions," Journal of Petroleum Science and Engineering, vol. 59, no. 3, pp. 779-793, 2009.

[10] K. K. Chong, W. V. Grieser, A. Passman, H. C. Tamayo, N. Modeland, and B. E. Burke, "A completions guide book to shaleplay development: a review of successful approaches toward shale-play stimulation in the last two decades," in Proceedings of the Canadian Unconventional Resources and International Petroleum Conference, Calgary, Alberta, Canada.

[11] X. Jin, S. N. Shah, J.-C. Roegiers, and B. Zhang, "Fracability evaluation in shale reservoirs - An integrated petrophysics and geomechanics approach," in Proceedings of the SPE Hydraulic Fracturing Technology Conference 2014, pp. 153-166, February 2014.

[12] B. Lawn, Fracture of Brittle Solids, Cambridge University Press, New York, NY, USA, 1993.

[13] Y. Chen, Y. Jin, and M. Chen, "A rock brittleness evaluation method based on energy dissipation," Lixue Xuebao/Chinese Journal of Theoretical and Applied Mechanics, vol. 47, no. 6, pp. 984-993, 2015.

[14] M. Cai, P. K. Kaiser, Y. Tasaka, T. Maejima, H. Morioka, and M. Minami, "Generalized crack initiation and crack damage stress thresholds of brittle rock masses near underground excavations," International Journal of Rock Mechanics and Mining Sciences, vol. 41, no. 5, pp. 833-847, 2004.

[15] R. Altindag, "Correlation of specific energy with rock brittleness concepts on rock cutting," Journal of The South African Institute of Mining and Metallurgy, vol. 103, no. 3, pp. 163-171, 2003.

[16] L. G. Tham, H. Liu, C. A. Tang, P. K. K. Lee, and Y. Tsui, "On tension failure of 2-D rock specimens and associated acoustic emission," Rock Mechanics and Rock Engineering, vol. 38, no. 1, pp. 1-19, 2005.

[17] D. Zhang, P. G. Ranjith, and M. S. A. Perera, "The brittleness indices used in rock mechanics and their application in shale hydraulic fracturing: A review," Journal of Petroleum Science and Engineering, vol. 143, pp. 158-170, 2016.

[18] Q. B. Zhang and J. Zhao, "Effect of loading rate on fracture toughness and failure micromechanisms in marble," Engineering Fracture Mechanics, vol. 102, pp. 288-309, 2013.

[19] B. Hou, M. Chen, W. Cheng, and C. Diao, "Investigation of Hydraulic Fracture Networks in Shale Gas Reservoirs with Random Fractures," Arabian Journal for Science and Engineering, vol. 41, no. 7, pp. 2681-2691, 2016. 

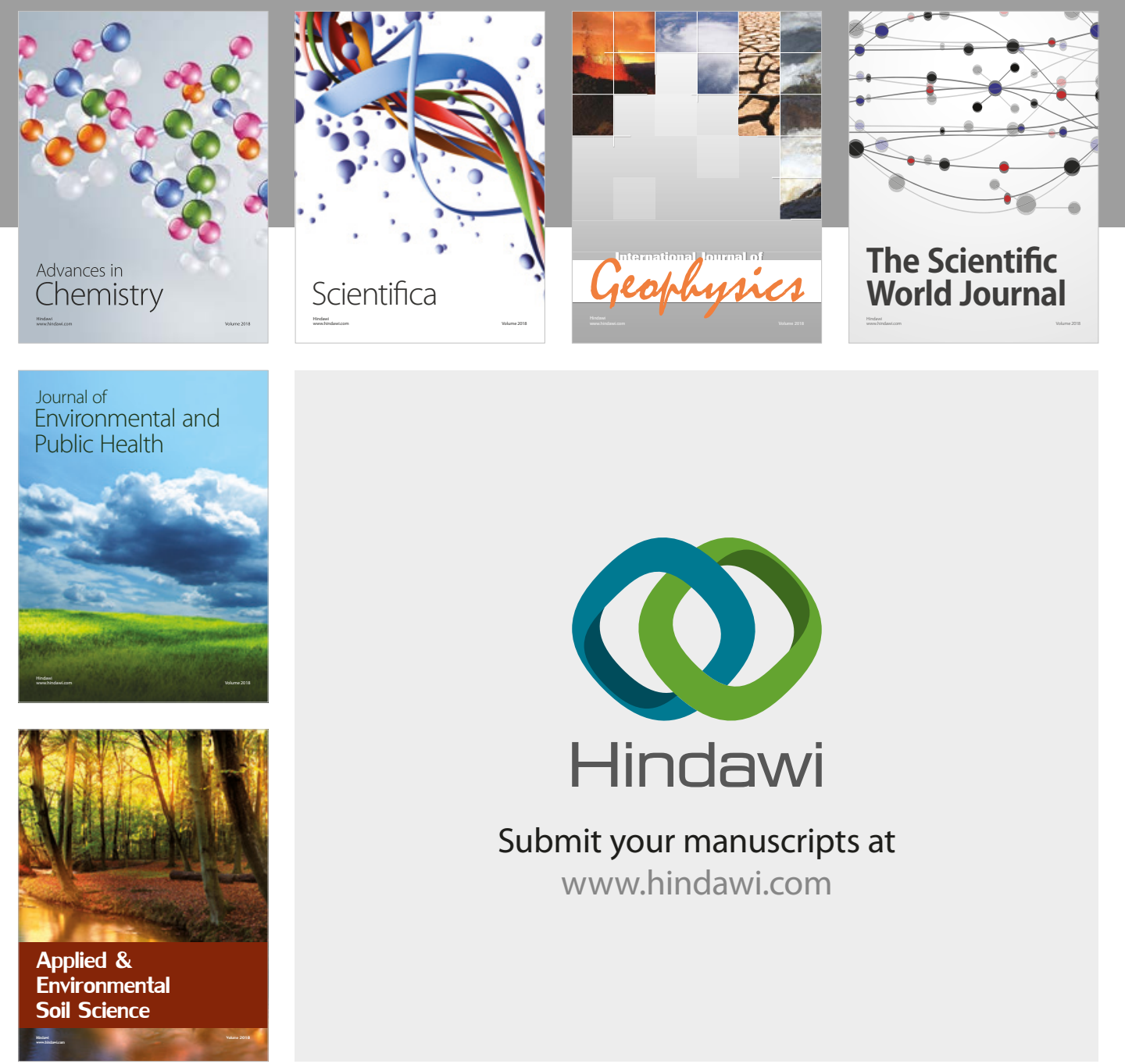

The Scientific

\section{World Journal}
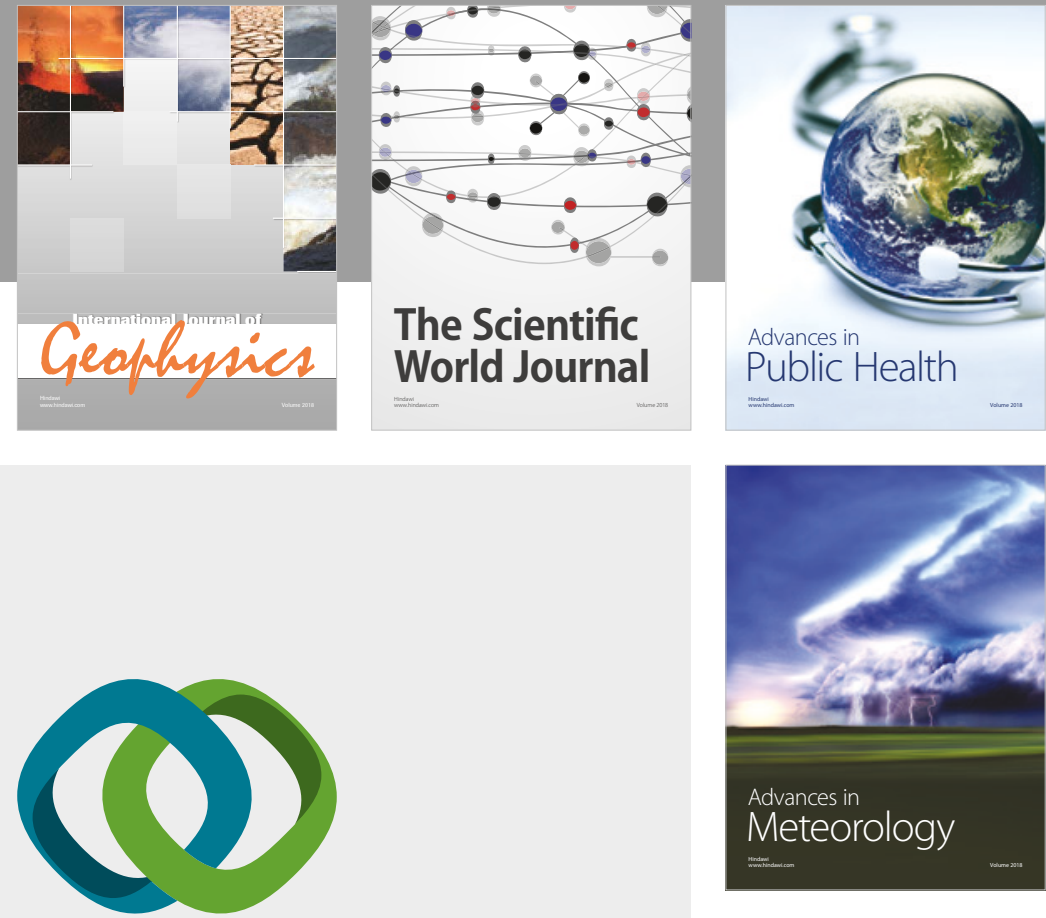

Advan

Public Health

\section{Hindawi}

Submit your manuscripts at

www.hindawi.com
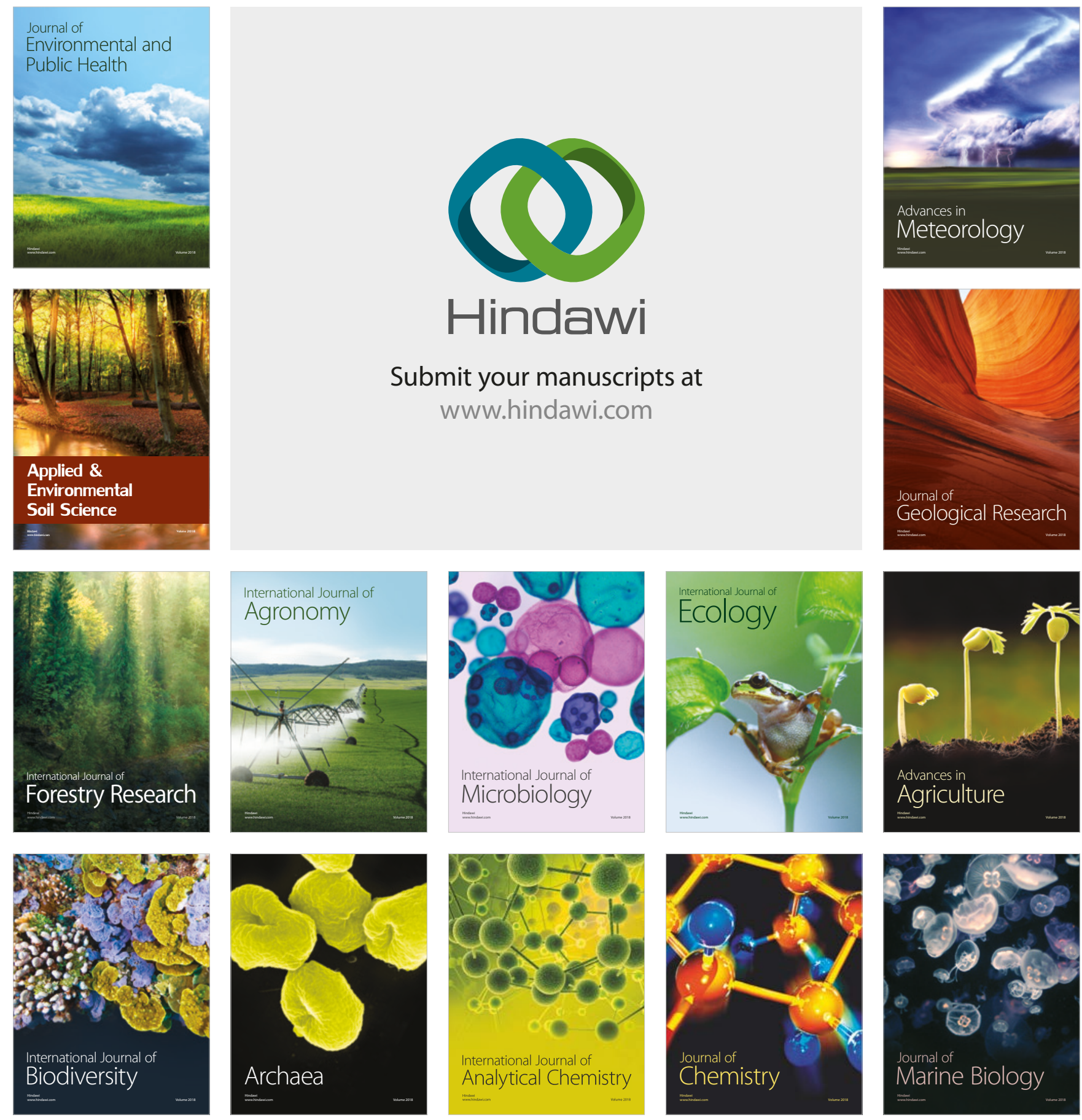